\title{
Exploring barriers that nurses experience to enrolment for a postgraduate nursing qualification at a higher education institution in South Africa
}

\author{
M O Mbombi, ${ }^{1}$ MCur; T M Mothiba, ${ }^{2} \mathrm{PhD}$ \\ ${ }^{1}$ Department of Nursing Science, School of Health Care Sciences, Faculty of Health Sciences, University of Limpopo, Polokwane, South Africa \\ ${ }^{2}$ Executive Dean's Office, Faculty of Health Sciences, University of Limpopo, Polokwane, South Africa
}

Corresponding author: M O Mbombi (masenyani.mbombi@ul.ac.za)

\begin{abstract}
Background. Professional nurses with a Master's degree have shown competence in improving quality and continuous care, including palliative care, mental health, post-transplant care and central venous care. However, nursing departments at South African (SA) universities experience challenges, such as fewer students in postgraduate courses, including Master's studies.

Objective. To explore and describe the barriers that nurses experience regarding enrolment for postgraduate qualifications.

Methods. A qualitative explorative-descriptive approach was used to examine experiences of nurses regarding enrolment for postgraduate studies at a tertiary hospital in Limpopo Province, SA. Purposive sampling was used to select professional nurses at this tertiary hospital. Data were collected using a semi-structured interview, which was analysed by Tesch's open coding of data analysis.

Results. It was found that professional nurses' lack of information regarding postgraduate studies and lack of funding were barriers to enrolment, as well as not being satisfied with the current educational status and not seeing the purpose of obtaining a Master's degree.

Conclusion. The study findings highlight a need for workshops in Limpopo hospitals, especially regarding how to enrol and the importance of enrolling for postgraduate qualifications.
\end{abstract}

Afr J Health Professions Educ 2020;12(1):41-45. https://doi.org/10.7196/AJHPE.2020.v12i1.1126

Many academically orientated people aspire to achieve postgraduate qualifications. Higher-education institutions (HEIs) provide an opportunity for students to advance their academic careers and to achieve the desired professional development. This article addresses only two opportunities (Honours and Master's degree qualifications) for professional development in nursing as a discipline of the healthcare system. These two qualifications have proven to be beneficial in clinical nursing education and the practice stream, healthcare leadership and administration, as well as the education stream. ${ }^{[1]}$ Depending on the nursing stream, a professional nurse can enrol in postgraduate courses for different reasons, including promotion, improving health and technology, personal enrichment and career development. ${ }^{[2,3]}$ However, this does not seem to be the case for nurse clinical practitioners at a tertiary hospital in Limpopo Province, South Africa (SA). This institution of higher learning has continuously indicated a concern regarding the low enrolment of professional nurses for postgraduate studies. In this context, a postgraduate qualification, therefore, refers to an Honours and a Master's degree in SA higher institutions.

Master's qualifications enhance the educative, research and administrative roles of the professional nurse. ${ }^{[1]}$ Therefore, suggesting that having more clinically trained professional nurses with a Master's qualification provides an opportunity for sustaining the nursing profession and improving the healthcare institution. ${ }^{[4]} \mathrm{A}$ nursing practitioner with a Master's qualification enhances a patient's safety needs in hospital. ${ }^{[1]}$ Furthermore, interest in a postgraduate qualification is motivated by possible opportunities, such as business opportunities, and research and collaboration with academics and professionals in the same field of practice or the same discipline. ${ }^{[3,5]}$ Therefore, increasing the enrolment of professional nurses becomes important for both clinical and academic institutions (especially considering the growing number of academics who are due to retire). However, this objective seems to be impossible owing to various barriers.

Nevertheless, for professional nurses to take advantage of the benefits of a clinical Master's degree in nursing, one needs to eliminate the barriers to enrolling for this postgraduate qualification. Smith et al ${ }^{[2]}$ identified a lack of time to study, lack of finances, workload, programme limitations and family commitments as barriers to part-time study for a clinical Master's degree in physiotherapy in Canada. In Kenya ${ }^{[6]}$ barriers for professional nurses who undertake postgraduate courses are the cost of the course, family commitments, course workload and lack of remuneration directly after obtaining the postgraduate degree. In contrast, a study in the USA indicated that there is an increase in nurses enrolling for an advanced nursing qualification, e.g. Master's and doctoral degrees. ${ }^{[7]}$ The authors further outlined that family, finances, support from employers, the complicated application process of the education institutions and age ( $>38$ years) were perceived by other professional nurses as barriers to enrolling for a postgraduate nursing qualification. ${ }^{[7]}$ While employment and education institutions are barriers to enrolling for an advanced degree (Master's) in nursing, especially when there is little or no collaboration between institutions, these contribute to the shortages of nurses in faculties of health sciences. ${ }^{[8]}$

In SA, despite the reported rise in enrolment for postgraduate studies, ${ }^{[9]}$ the nursing profession continues to experience inconsistencies in enrolment and throughput for postgraduate nursing qualifications, particularly Master's and doctoral degrees. ${ }^{[10]}$ These inconsistencies are due to the 
poor adjustment of health practitioners in academic institutions. ${ }^{[11]}$ It would seem as though there are more professional nurses with Master's degrees in academic institutions than in the clinical environment. There has also been concern regarding professional nurses not enrolling for Master's studies. ${ }^{[12]}$ This concern raises questions regarding the barriers to enrolment of professional nurses for Master's studies at higher institutions. The growing health complexity in the province necessitates exploring the barriers experienced by professional nurses, as it is necessary to increase the number of policymakers, academic authors, nurse educators and administrators. Therefore, the objective of this study was to explore and describe barriers experienced by professional nurses regarding enrolment for postgraduate nursing studies.

The study findings are anticipated to create an awareness in SA schools of nursing, the SA Nursing Council (SANC) and the Department of Health (DoH) regarding recognition of Master's qualifications in the clinical setting as an important requirement for the improvement of healthcare institutions.

\section{Methods}

A qualitative research approach was used to explore barriers that nurses experience to enrolment for a postgraduate nursing qualification at HEIs. Explorative and descriptive research designs were applied to achieve the research aim.

\section{Population and sampling}

The population comprised all professional nurses who were working in nursing care units at a tertiary hospital. The study sample consisted of 20 professional nurses, using a non-probability purposive homogeneous sampling method. Only professional nurses who could enrol for postgraduate studies at a tertiary institution were selected to participate in the study.

\section{Study site}

The study was conducted at a tertiary hospital in Capricorn District of Limpopo Province. This hospital caters for all patients transferred from clinics and primary and secondary hospitals in the province. The hospital has many professional nurses who qualify to register for postgraduate studies.

\section{Data collection}

A semi-structured interview guide was used for data collection. Quality of data was ensured by the listening skills of the participants describing the barriers they experience when they want to enrol for postgraduate studies, and also probing professional nurses for in-depth data regarding the barriers. Reflective skills were used to summarise, obtain clarity and further stimulate professional nurses to describe in detail the barriers to enrolment. ${ }^{[13]}$ For example: 'You said you fail to enrol in a Master's programme due to the workload. Could you kindly elaborate further?' The authors showed interest in the participants by using responses, such as 'ooh' and 'okay', to interact. Interviews lasted 35 - 45 minutes and data were saturated in 13 professional nurses. A digital audiotape was used to capture all interviews, which were conducted in a quiet cubicle in the hospital - free from noise and disturbances. Data collection was completed in 30 days in 2016.

\section{Measures to ensure trustworthiness}

Four criteria of trustworthiness were adhered to in the study to ensure accuracy and the true value of the study findings. ${ }^{[14]}$ The researcher
(MOM) used a purposive sampling method to enhance transferability and select professional nurses to participate in the study. Independent coding of the results was done by the second author to enhance dependability. Confirmability was ensured by writing field notes and using a voice recorder during semi-structured one-on-one interviews - the voice recordings were preserved for further auditing by external auditors. Credibility was obtained by prolonged engagement, during which the researcher interviewed participants; data collection was completed in a month.

\section{Data analysis}

Tesch's open coding method, as described by Creswell, ${ }^{[15]}$ was used to analyse data. Data were condensed into discrete parts, closely examined and compared for similarities and differences. Questions were asked about experiences as reflected in the data. Three themes emerged from the study findings: employment-related barriers, HEI-related barriers and personal barriers.

\section{Ethical approval}

Ethical approval was obtained from the Turfloop Research Ethics Committee (ref. no. TREC/185/2016). Permission to conduct the study at a tertiary hospital in Limpopo was granted by the Limpopo Department of Health. Professional nurses gave informed consent and voluntarily signed the consent form before participation in the interview sessions. To ensure confidentiality, we stored the audiotaped interview records where only authorised personnel could obtain access. Professional nurses were allocated code numbers to ensure anonymity. The employer permitted professional nurses to be part of the study, which assured their safety while participating in the study. All professional nurses were treated equally. The nurses could recuse themselves from the interview sessions without coercion to continue. There were no financial benefits for participants, and nurses were assured that participation bore no psychological and socioeconomic risks.

\section{Results and discussion \\ Demographic data of professional nurses}

Table 1 summarises the demographic data of professional nurses who participated in the study. The results of the study are summarised in Table 2.

\begin{tabular}{ll}
\multicolumn{2}{l}{ Table 1. Demographic data of professional nurses } \\
\hline Demographic variables & Population, $\boldsymbol{n}(\%)$ \\
\hline Qualifications & \\
Basic nursing degree (Honours) & $13(65)$ \\
$\quad$ Postgraduate diploma & $7(35)$ \\
Gender & \\
$\quad$ Male & $6(30)$ \\
Female & $14(70)$ \\
Working experience, years & \\
$2-5$ & $3(15)$ \\
$6-9$ & $7(35)$ \\
$10-13$ & $6(30)$ \\
$\geq 14$ & $4(20)$ \\
Total & 20
\end{tabular}




\begin{tabular}{ll} 
Table 2. Results of the study & \\
\hline Themes & Subthemes \\
\hline 1. Employment-related barriers & - Financial gain after obtaining a Master's degree \\
& - Workload v. shortage of staff \\
& - Lack of recognition of academic achievement by management \\
2. Barriers relating to higher-education institutions & - Lack of information regarding the degree \\
& - Requirements for postgraduate courses viewed as difficult to achieve \\
3. Personal barriers & - Lack of finances v. family responsibilities \\
& - Lack of study passion v. satisfaction with current job status
\end{tabular}

\section{Theme 1: Employment-related barriers}

The findings revealed various factors that hinder professional nurses from enrolling for postgraduate studies at HEIs: work-related factors, such as workload and shortage of staff; and personal factors, such as lack of passion for studying for a postgraduate degree. Lack of support by management was also indicated as a factor hindering professional self-development for professional nurses to upgrade their skills for career development and personal growth. The subthemes are discussed below.

\section{Financial gain after obtaining a Master's degree}

Professional nurses verbalised that there is no financial gain after obtaining a postgraduate qualification, and therefore felt that continuing education at the postgraduate level is a waste of time. They consequently felt discouraged to enrol for postgraduate studies:

'... why should I use my family money to study for a degree that will not benefit me financially ... ? (Participant 8 )

'There are no financial benefits after getting the degree ... don't see a need to enrol for such a course.' (Participant 14)

Similarly, it was found that lack of direct remuneration is a barrier to enrolling for a postgraduate qualification in Australia. ${ }^{[16]}$ Lack of remuneration discourages nurses from enrolling in postgraduate courses, as there are no prospects of career advancement, such as increased financial benefits, after obtaining a postgraduate degree. ${ }^{[17]}$

\section{Work overload v. staff shortage}

The workload that results from staff shortages in nursing care units was indicated as a reason for professional nurses not to enrol for postgraduate studies - they did not have enough time because they were exhausted:

'When will you study ... the ward is always full and all those patients are expecting that you take care of them.' (Participant 2)

'The unit is always full of patients ... at times only one professional nurse has to run the whole unit along with two staff nurses. At the end of the day you become so exhausted, and thinking of enrolling for the postgraduate course is a dream that one will never achieve.' (Participant 5)

Smith et al.$^{[2]}$ indicated that insufficient rest time affects one's health, which may result in discontinuation of postgraduate studies. According to Fang et al., ${ }^{[16]}$ a person with a heavy workload and family responsibilities might struggle to find time to study.

\section{Lack of recognition of academic achievement by management}

The findings revealed that the $\mathrm{DoH}$ attaches no value to a postgraduate qualification, such as a Master's degree in nursing. The Department does not increase one's salary level on completion of the degree. Participants also indicated that the SANC sees no value in nurses studying towards a Master's degree, which can be demotivating:

'Why should I get a Master's ... our DoH does not value the qualification ... they won't increase your salary. Therefore, it will be a waste of time for me to study towards the achievement of that qualification.' (Participant 4) 'The SANC does not recognise the qualification because it is not registering it in their system. They do not even make recommendations that the course should be given by nurse managers as in other countries as I have heard.' (Participant 12)

The findings are consistent with those of Hoffman and Julie, ${ }^{[11]}$ who indicated that career progression is an intrinsic motivator for a person to enrol in a Master's programme at the University of the Western Cape. Poor financial compensation and a non-competitive salary are barriers to studying towards a postgraduate nursing degree.

\section{Theme 2: Barriers relating to higher-education institutions}

Professional nurses described barriers that relate to HEIs as those regarding enrolment in postgraduate nursing studies.

\section{Lack of information on postgraduate studies}

Professional nurses indicated that there was a lack of information on postgraduate studies, especially regarding the Master's degree in nursing:

'I do not know what they want for one to register for a Master's degree.' (Participant 7)

'I only have a diploma, not a degree; they will not allow me even if I want to register it.' (Participant 13)

A lack of course information on websites and the complicated application process of education institutions could become barriers to enrolment in postgraduate studies. ${ }^{[17]}$ Most professionals want to pursue postgraduate courses, but lack information about admission criteria. ${ }^{[6]}$

\section{Requirements for postgraduate courses viewed as difficult to achieve}

Professional nurses indicated that it was not easy to enter Master's studies, as most of them did not qualify when considering admission requirements:

'... they want 60 marks average from the basic degree and that is the problem, because we do not have in my case my performance - in the final year it was not satisfactory in the basic degree that I have obtained.' (Participant 14)

'... eish, my final-year results of my former degree are not good and if you 
want to enrol for a Master's degree you should have obtained your junior degree at least with $60 \%$ and above ... .' (Participant 10)

Smith et al. ${ }^{[2]}$ support the findings by stating that barriers to enrolment in postgraduate studies are institutional and personal - institutional refers to policies and practices that make it difficult for a person to access courses at tertiary institutions. Dam ${ }^{[17]}$ agrees with Smith et al'. ${ }^{[2]}$ findings by highlighting that higher-institution entry requirements block access to a postgraduate course. Matsolo et al. ${ }^{[18]}$ confirmed that poor entry-level marks became a barrier to postgraduate studies, which was confirmed by Lakati et al. ${ }^{[6]}$

\section{Theme 3: Personal barriers}

Professional nurses described personal barriers to enrolling in postgraduate nursing studies

\section{Lack of finances $v$. family responsibilities}

Some professional nurses indicated that lack of financial support, such as insufficient scholarships and bursaries, was a barrier to enrolling in postgraduate courses, while others highlighted that their families' financial responsibilities were the reason for not enrolling in postgraduate degrees at HEIs. This view was supported by the following participants:

'I cannot use my family money for my personal studies while there is a dire need in the family to use such money. For example, I have to provide for the basic needs of my family members, which require finances.' (Participant 6)

'If there can be a lot of scholarships and bursaries to assist us to enrol for the postgraduate course, then I can take that option and register because it will not put any strain on my family finances.' (Participant 12)

Some authors ${ }^{[2,8]}$ support the findings that an advanced degree may be financially costly and, as such, lack of finances becomes a barrier to enrolling in the postgraduate course. However, Matsolo et al. ${ }^{[18]}$ indicated that financial instability has an impact on racial enrolment in most academic institutions, as some students of specific races are restricted by lack of finances to enrol in courses at universities. Others ${ }^{[16,19]}$ indicated that overwhelming responsibilities, including spouse, parental and employers' roles, are barriers that confront postgraduate students. In support of the findings, challenges have been highlighted, e.g. having to support children and families as a part-time female student. ${ }^{[20,21]}$ These challenges resulted in an imbalance between personal life (family), employment and students' responsibilities, which became a burden.

\section{Lack of study passion v. satisfaction with current job status}

Some professional nurses who qualify to enrol in postgraduate courses at HEIs indicated lack of interest to further their studies, mainly because they were satisfied with their current educational status and employment, and therefore see no need to do so:

'Study Master's to do what ... am still happy with my position in the hospital and my current academic achievement.' (Participant 9)

'Enrol Master's for what reason; I do not like research ... and there will be no changes in my job title after obtaining that Master's.' (Participant 5)

In support of the findings, Bani-Khaleb and Diab ${ }^{[22]}$ indicated that personal interest in learning was a factor that influenced Jordanian students' choice of enrolling at university to study further. Other findings show that in Gauteng Province, SA, 77\% of blacks are satisfied with their current educational status, and therefore do not see the need to further their studies. Matsolo et al.$^{[18]}$ concur with the findings by stating that lack of commitment seems to be another factor hindering students from furthering their studies. $\operatorname{Lin}^{[19]}$ indicated that personal attitudes and self-perceptions with regard to continuing education are blamed for hindering people's personal development.

\section{Recommendations}

The study findings recommend a support programme by the $\mathrm{DoH}$ and the SANC related to continuing education, especially for professional nurses to enrol in postgraduate courses that lead to upscaling of their skills to provide quality care to patients. The support should include awarding study leave for time off from work during enrolment as a postgraduate student. Furthermore, there should be an increase in financial scholarships and bursaries by the DoH and universities/Department of Higher Education and Training to support professional nurses with financial problems and family responsibilities, but who nonetheless pursue postgraduate studies. Universities should be aggressive in raising awareness of programmes through roadshows to ensure that professional nurses are knowledgeable regarding the postgraduate qualification. Workshops should be conducted to educate nurses, remind the SANC and inform the DoH regarding the benefits of postgraduate studies related to patient care. Authorities such as the DoH and the SANC should indicate that postgraduate studies, e.g. a Master's degree, are a prerequisite for leadership positions, and that all those who qualify for Master's studies should be promoted. Lastly, there should be collaboration between academic institutions and employers regarding academic programmes that could have an impact on nursing care.

\section{Conclusion}

Employment and institutional and personal factors were described as barriers experienced by professional nurses to enrolling for postgraduate studies. Those who are interested to pursue postgraduate studies, including a Master's degree, fail to enrol owing to various factors in the employment area, coupled with family responsibilities. Lack of support and lack of recognition of postgraduate qualifications by authorities, such as government leadership and the SANC, are major barriers to enrolment of professional nurses in postgraduate nursing studies.

\section{Declaration. None.}

Acknowledgements. The authors would like to acknowledge all nurses who participated in the study to make it a success. We further acknowledge the efforts of final-year nursing students of the University of Limpopo, who assisted in the data collection.

Author contributions. MOM: assisted in the initial conceptualisation and the finalisation of the manuscript. TMM: assisted in the second draft and refinement of the manuscript for publication.

Funding. None.

Conflicts of interest. None. 
2. Smith AN, Boyd LD, Rogers CM, le Jeune RC. Self-perceptions of value, barriers, and motivations for graduate education among dental hygienists. J Dent Educ 2016;80(9):1033-1040.

. Cotterill-Walker SM. Where is the evidence that Master's level nursing education makes a difference to patien care? J Nurse Educ Today 2010;32:57-64. https://doi.org/10.1016/j.nedt.2011.02.001

4. Matthias AD. Making the case for differentiation of registered nurse practice: Historical perspective meets contemporary efforts. J Nurs Educ Prac 2015;5(4):108-114. https://doi.org/10.5430/jnep.v5n4p108

5. Fourie-Malherbe M, Albertyn R, Bitzer E. Postgraduate Supervision: Future Foci for the Knowledge Society Stellenbosch: African Sun Media, 2016.

6. Lakati A, Ngatia P, Mbindyo C, Mukami D, Oywer E. Barriers to enrolment into a professional upgrading program for enrolled nurses in Kenya. Pan Afr Med J 2012;13(1):1-11.

7. Kovner CT, Brewer C, Katigbak C, Djukic M, Fatehi F. Charting the course for nurses' achievement of higher education levels. J Prof Nurs 2012;28(6):333-343. https://doi.org/10.1016/j.profnurs.2012.04.021

8. Cathro H. Pursuing graduate studies in nursing education: Driving and restraining forces. J Issues Nurs 2011;16(3):7. https://doi.org/10.3912/OJIN

9. Academy of Science of South Africa. Consensus Report on PhD Study. Pretoria: ASSAf, 2010.

10. Council on Higher Education. Vital Statistics of Public Higher Education. Pretoria: CHE, 2015.

11. Hoffman JC, Julie H. The academic transitional experiences of Master's students at the University of Western Cape. Curationis 2012;35(1):1-8. https://doi.org/10.4102/curationis.v35i1.33

12. Department of Nursing Science. 2012 - 2015 Report. Polokwane: University of Limpopo, 2015

12. Depark 3rd ed. Cape Town: Juta, 2012.
14. Babbie E, Mouton J. The Practice of Social Research. Cape Town: Oxford University Press, 2009.

15. Creswell JW. Qualitative Inquiry and Research Design: Choosing Among Five Approaches. 2nd ed. Thousan Oaks, CA: SAGE, 2014.

16. Fang D, Bednash GD, Arietti R. Identifying barriers and facilitators to nurse faculty careers for PhD nursing students. J Prof Nurs 2016;32(3):193-201. https:/doi.org/10.1016/j.profnurs.2015.10.001

17. Dam SA. What matters most? Factors influencing choice of a student affairs Master's program. Master's thesis. Lincoln: University of Nebraska, 2014. http://digitalcommons.unl.edu/cehsedaddiss/176 (accessed 6 March 2020)

18. Matsolo MP, Ningpuanyeh WC, Susuman AS. Factors affecting enrolment rate of students in higher education. J Asian Afr Stud 2018;53(1):63-80. https://doi.org/10.1177/0021909616657369

19. Lin X. Barriers and challenges of female adult students enrolled in higher education: A literature review. High Educ Stud 2016;6(2):119-126. https://doi.org/10.5539/hes.v6n2p119

20. Council of Australian Postgraduate Association. Postgraduate Reports. Melbourne: CAPA, 2011

21. Founler GC. Students' Progression to Post-graduate Studies: An Exploratory Study on Demographic Attributes
21 Fowler GC. Students' Progression to Post-graduate Studies: An Exploratory Study on Demogr
Among Psychology Honours Students at the University of Cape Town. Cape Town: UCT, 2013.

2. Turki AA, Bani-Khaled D. Factors that influence Jordanian EFL students' choice of a university. Arab World English 2014;5(1):247-259

Accepted 4 September 2019. 